\section{Guillermo, El Mono}

“No perdono a la muerte enamorada, no perdono a la vida desatenta, no perdono a la tierra, ni a la nada". Miguel Hernández

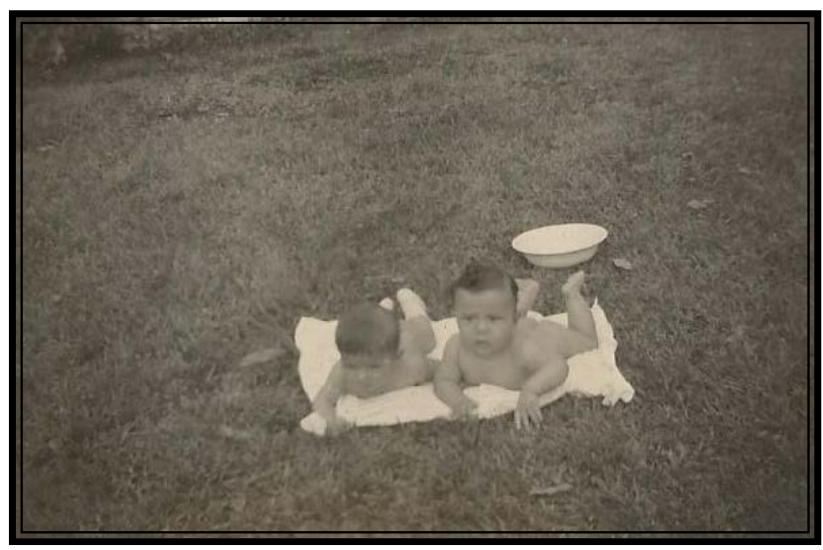

Es mi deseo hablar de El Mono, no de Guillermo. No sé por qué, pero siempre, cada vez que alguien me preguntaba por Guillermo, mis recuerdos y mis emociones quedaban suspendidas por unos segundos hasta que, un mensaje recóndito de alguna parte de mi memoria, me recordaba que la pregunta era por El Mono.

Así le decíamos en la familia y es de El Mono que deseo hablar; desde la evocación de dos momentos que son una especie de paréntesis en su vida: él, a los 17 años y él a los 64. Dejo a los poetas, a los literatos, a los críticos de oficio, que comenten su obra, que hagan juicios sobre su estética; ellos saben mucho más que yo de estos menesteres; por eso, es mi deseo hablar de El Mono, no de Guillermo.

El 26 de septiembre de 2016 falleció y casi como nunca los versos del peruano César Vallejo retumbaron en mis oídos, pues hay golpes en la vida, tan fuertes, como del odio de Dios; son pocos, pero son... Parecía increíble que hubiera sucedido, era absurdo que él, grandote, con ese caminar pausado, perezoso, que se tomaba una jarra de café negro antes de desayunar, que miraba en acogedora ausencia, en lejanía, como si presintiera un horizonte de horizontes, en metáfora de viaje hubiese muerto. Cada vez que lo veía caminar, con su espalda ligeramente encorvada, con sus pesadas pisadas, con esa tranquilidad enorme ante el afán de la vida, recordaba a esos campesinos de los plantíos retratados por Faulkner, en las zonas agrícolas algodoneras del sur estadounidense, a esos plantadores.

Gringo pobre, decía mi mamá, al referirse a él; luego sonreía. Todas las mamás nacen sabias y con los años su sapiencia se agudiza sin alardes ni escándalos; por ello, El Mono siempre será eso en el imaginario familiar.

Y a veces creo que no sólo en este imaginario, sino en el de muchas personas, como en el de aquel pescador cartagenero que, una noche, por el Muelle de los Pegasos, mientras caminábamos buscando un jugo, patacón y queso le gritaba con insistencia: igringo, go home!, igringo, go home! Lo hacía en todos los tonos y volúmenes posibles, en una cantinela permanente y $\mathrm{El}$ Mono no se inmutaba... hasta que el criollo cartagenero le dijo en perfecto y entendible español: gringo, por qué no te vas para tu casa y El Mono le contestó, también en perfecto y entendible español: porque esta también es mi casa, hijo de puta. Ya podrán suponer la cara del cansino contertulio y la risotada de algunos trasnochadores que se encontraban por ahí.

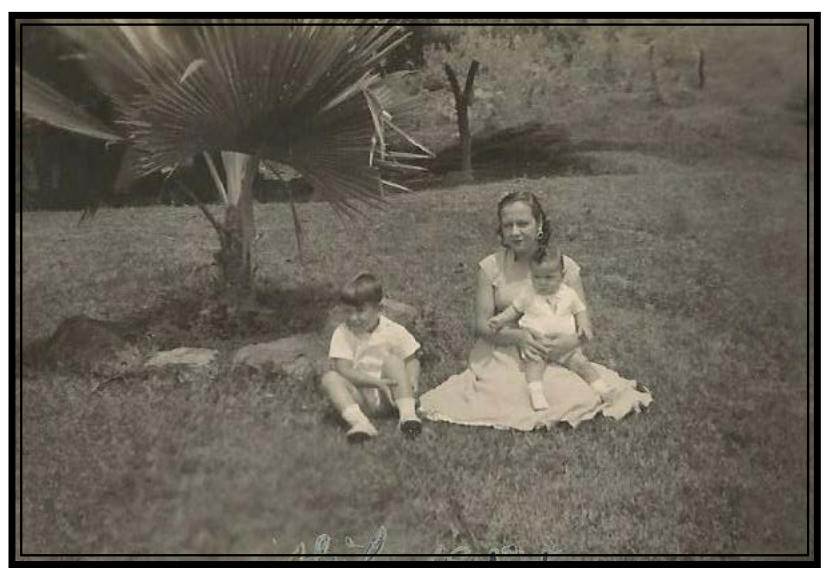


Mi primer recuerdo bien definido de El Mono lo sitúa en el antejardín de la casa del barrio El Progreso, en Garzón, con una barba rala, el cabello algo largo y desordenado, muy delgado, sentado en una de esas sillitas de madera y lona de listas de colores tan comunes en nuestras casas tropicales, con los pies encaramados en la verja, con un cigarrillo 'Pielroja' entre sus dedos (tal vez la única época de fumador, creo que más por moda que por vocación), mirando sin prisa a todo aquel que pasara por la calle y absorto en sus maquinaciones poéticas.

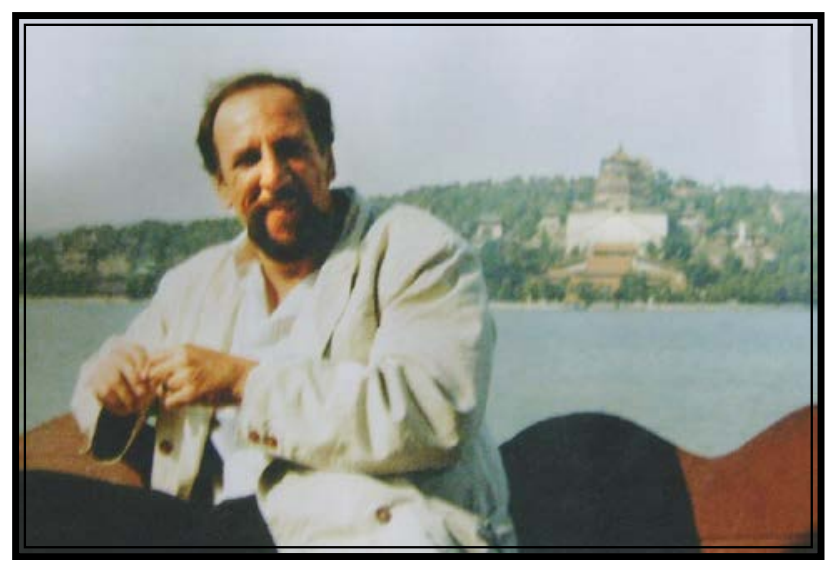

A pesar de estar sentado con placidez, de durar callado por horas y horas, lo que se percibía era una protesta profunda, un reto provocador, una mirada beligerante, contra toda la pacatería y falsa candidez de un pueblo ahogado en rezos y culpas morales. En eseentonces, ElMono formaba parte de una generación que escuchaba los ecos de la Revolución Cubana, que veía al hipismo todavía como algo extraño y de impostura cultural, una generación compuesta por muy pocos muchachos que se atrevía a expresar -casi con el mismo escándalo de una tacada de billar a las dos de la mañana- su desacuerdo con el orden pretendidamente legítimo de las cosas.

No resulta nada extraño que en su diatriba contra la escuela afirmara que le sabía a "jaula de pájaro trizado por el polvo", que declarara con altivez que nada le debía a la escuela, porque nada le había enseñado, y que anunciara sin rodeos que estaba habitada por "moralistas sin sotana" donde "loros parlantes hablaban de todo porque nada sabían". Por ello su verdadera liberación lo llevó a testificar que pasó por sus aulas "como el prisionero que devora la luz a través de las rejas".
Como es lógico suponer, esa rebeldía perenne, esa obstinación por pensar de otra manera, le impusieron una suerte de condena de ostracismo y casi de exilio. El mundo todavía era ancho y ajeno. Demasiado ancho, demasiado ajeno.

Aún era menor de edad, aún tenía la barba incipiente, aún el mundo se refería y se restringía y se agotaba en el paisaje pueblerino, cuando El Mono salió de casa para ir a trabajar a Cartagena, mil kilómetros más allá de la imaginación de aquel entonces. Las lágrimas de mamá, más que una invitación a que se quedara, fueron una promesa cierta para que retornara.

Nunca regresó a esa casa con el antejardín y la verja desde donde contempló el mundo; cuando lo hizo ya vivíamos en Neiva. Regresó mayor de edad, con el sabor de otros paisajes en sus ojos, con nuevas palabras y nuevas convicciones más radicales sobre lo que era el oficio de escribir desde el asombro, la duda y los intersticios de la vida cotidiana.

A mí, que entonces tenía quince años, me trajo un regalo indescriptible del que me ufanaba en soledad en el patio extenso del caserón donde vivíamos en el centro de la ciudad: una grabadora portátil, de esas pesadas, que requería 8 pilas de las gordas para funcionar que, es obvio, se agotaban con rapidez. Y dos cassetes: uno de Silvio Rodríguez (verdadera sorpresa musical para mí) y otro de... ¡Janis Joplin!, con su voz escandalosa, pastosa, casi anticantante.

Esas imágenes quedaron por siempre en la retina de mi recuerdo... También las últimas, pocos días antes de que El Mono decidiera soltarse de este mundo, a pesar de estar tan aferrado a él.

Entre estos dos momentos, como un largo pero explicativo paréntesis, existe un caudal de casi 50 años. Por las playas, arroyos, recodos y crecientes de más de dieciocho mil días han pasado tantas cosas y tantas cosas dejaron de pasar.

Asesinato de Lennon, derrumbe del imperio soviético, caída del muro de Berlín, advenimiento y triunfo de la internet, uso de telefonía móvil, rápida génesis y muerte del walkman, el disquete, la revolución del compact disc, DVD para ver más 
y oír más, Mandela y el Apartheid, la memoria USB con capacidad casi infinita de almacenamiento, la localización por GPS, el premio Nobel a Gabriel García Márquez, el ataque a las Torres Gemelas, Osama Bin Ladem y su convincente amenaza mundial, la elección popular de Allende en Chile, su derrocamiento y dictadura sangrienta de Pinochet, la inútil Guerra de las Malvinas, el exterminio feroz de la Unión Patriótica, Pablo Escobar y sus oficinas de cobro sicarial, la alabada selección de fútbol de Maturana, la selección de fútbol de Pekerman y sus estrellas, el discurso del Comandante Chávez, el indescriptible y torpe Subcomandante Maduro, el tortuoso proceso de paz con las Fuerzas Armadas Revolucionarias de Colombia, Uribe hasta en la sopa, Santos y su póker, el proceso ocho mil y mucho más, el Ejército de Liberación Nacional, la llegada de la televisión a color, la magia de Pelé, el escándalo de Maradona, la figura icónica del Che Guevara, ETA e IRA en otras latitudes, el escandaloso Watergate, la derrota, nunca superada por los estadounidenses, en Vietnam, la diversión casera delas videoconsolas y videojuegos, el casto Sida, el antiséptico bebé probeta, la tenebrosa destrucción de Armero, la sangrienta toma del Palacio de Justicia, nacimiento, crecimiento y muerte del M-19, el peligro de extinción en Chernóbil, la siempre usada píldora, la masacre de Tiananmen, el telescopio espacial Hubble, la construcción del mapa básico del genoma humano, la oveja Dolly y su clonación, las masacres de Kosovo, el fin del mundo en forma de tsunami, Estado Islámico y su apoyo, el Euro, el escándalo musical de Woodstock, los paramilitares y su terror, la Intifada como símbolo de la lucha palestina, la moralista píldora abortiva, Windows y todos sus ambientes, siempre Mohammad Alí, el pobre rico Pambelé, Myke Tyson y sus puños de demolición, la entrega de la Madre Teresa de Calcuta, el fortalecedor Viagra, el terror nacional de las Autodefensas Unidas de Colombia, los asesinatos de Bernardo Jaramillo Ossa y Carlos Pizarro Leongómez, la séptima papeleta colombiana que ancló en

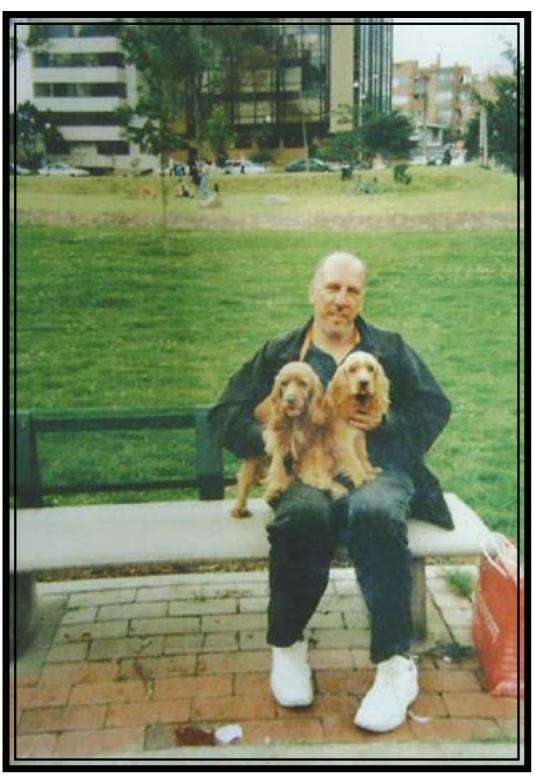

Constituyente, la golosa Mónica Lewinsky, la red a lo ancho y largo del mundo o www, el jardinero ciclista Lucho Herrera, Schumacher y su forma de opacar siempre a Juan Pablo Montoya, Kasparov y su genio ajedrecístico, Fisher y su excentricidad, el poderoso Putin, el veloz y antiecológico Concorde, iPod, iMac y toda las familia de los i, un solo billete simbolización del Euro, ascenso y caída de Lula da Silva, Arafat y su tenacidad, la Sonda Mars o la cienciaficción ahora, los leoninos Tratados de Libre Comercio, Fidel Castro y su imponencia, Bateman y su alegría, Obama y sus expectativas frustradas, Blu Ray para ver cine, la paranoia del H1N1, Wikipedia consultada pero negada, el imperial Google, el comunicativo Skype, Whatsapp o el uso alternativo del celular, la invasión a la privacidad del Facebook, la cultura visual del YouTube...

También pasaron y seguirán aquí Cartagena, China, Australia, Instituto Huilense de Cultura, Trilcey Talula, Declaración deamora las ventanas, $\mathrm{La}$ poesía de Matilde Espinosa, Diario de medianoche, Marx y los poetas, Puentes de niebla, El bosque de los bambúes, Mitos del Alto Magdalena, China Hoy, Lu Xu: Poemas; Tres poetas de habla inglesa, El solitario de la montaña vacía, El vuelo diabólico: poemas de vampiros y murciélagos; El árbol puro del río, El ermitaño de los lotos verdes, Puesto de combate, Trilce editores...

Por esos sarcasmos de la vida, los últimos días de El Mono y los míos, los vivimos en una clínica, pero se resolvieron de manera dramáticamente opuesta (¡cómo El Mono odiaba todos esos adverbios, palabras terminadas, sin necesidad $\mathrm{y}$ con facilidad, en -mente!). Los míos se prolongaron, los de él se agotaron.

El Mono estaba en la cama estrecha de un cuarto pequeño del séptimo amplio piso de una clínica enorme $y$ convulsa. Estaba sentado en la cama, encorvado como si una gigantesca y pesada cruz lo tuviera atado a una yunta plena 
de dolor. Pero su ánimo estaba aún ahí; su voz era recia, diáfana, optimista; su mirada mansa y plena de esperanza, así de vez en cuando se le escaparan algunos quejidos lastimeros, pero con la certeza de la vida, campante.

Hablamos de muchas cosas, de nuestra salud, de las excusas por no haber podido vernos antes, de mamá, de su estado de salud, del mío, de lo orgulloso que se sentía de su sobrino (mi hijo) y de cosas domésticas. Luego, quedamos solos por un espacio de más de una hora y la conversación derivó en aquellas cosas de las que no se acostumbra a hablar.

Comenté sobre la idea de la divinidad, de cómo ella nos rodea en el perfume de la flor, en el ocaso del sol, en la mirada del niño, así no aceptemos, sin fórmula racional de juicio, la presencia de algo que nos cubre, un cielo protector, dije; y quizá los que más me impactó por su convicción, fue su declaración tajante de creer, de tener fe, de aceptar sin vacilaciones la esencia de algo divino que nos rodea y nos hunde en la melodía de un coro de ángeles, no húmedos, sino abrazadores y cálidos que nos sostienen y alumbran por tránsitos oscuros.

Pronto la conversación viró hacia lo vulnerables y frágiles que somos; a cómo nuestra arrogancia y confianza en ese amasijo de hueso, carne y tendones, en esa estrepitosa reacción física y química, se ve hecha añicos en cualquier momento. Basta un pestañeo para que se produzca un vendaval.

Siempre seremos vulnerables en cuanto siempre tendremos una capacidad disminuida para enfrentar la vida, para anticiparnos a sus zarpazos, para resistir sus sacudidas y para recuperarnos desus golpes, fuela desconsoladora y serena conclusión a la que llegamos.

Tanta perfección, tanta inteligencia, tanta fortaleza, tanta capacidad de amar, tanta sensación de asombro, tanta tolerancia al dolor y tanta facilidad para rompernos o deteriorarnos: tanta fragilidad.

El tono y sentido de nuestras palabras, a pesar de todo, no se había vuelto lúgubre, ni desesperanzador; por el contrario, era una oda a la vida y su infinitud, al valor de lo elemental como verdadera raíz y esencia de nuestra existencia.

Por eso, al confesarle que durante mi encierro clínico había escrito sobre las cosas más simples $\mathrm{y}$, a veces, cursis, El Mono afirmó, con voz fresca como la del alquimista, su alegría por haber llegado a la semilla, a la génesis de todo lo que fue, es y será.

Lo elemental se vuelve fundamental, adquiere lugares primordiales, se hace evidente $\mathrm{y}$ complejamente fácil de entender, raigambre de la vida, agua que fluye, baña y refresca, que vivifica y que, a veces, arrasa y hunde y horada.

Ahora que escribo esto, presiento que entiendo el entusiasmo casi delirante de El Mono hacia lo elemental y sus hurras casi gritados por ello. Y cuando releo algunos de sus poemas, especulo desde mi ignorancia, que hablar, paladear, respirar y soñar con lo primario era su poético camino.

Por tanto, es natural que le cante a María, la que lava la ropa "entre susurros elementales / y abalorios de humildad", porque El Mono amaba todos sus "sueños de agua".

El tiempo pasó, sin afán, pero infalible, y la despedida era el anuncio del dolor y del llanto, era sorber esa imagen y petrificarla en el aire.

Tengo la certeza de que me volveré a sentar con él en la sombra de ese árbol "donde los pájaros tristes saborean / la fruta enloquecida del viento", o quizá "en el origen de la lluvia" o "en el borde de la luz", cuando "la muerte como un centinela de la amargura / nos traiga su grano de polvo".

Si El Mono escribió: "Lenta/ cae una hoja/ lo demás es silencio"; yo -si fuera poeta- escribiría: Lento/ cae un poeta/ lo demás se vuelve silencio. Sólo me queda decir, en perfecta armonía con Borges: a todos, tarde o temprano, nos va entregando la vida. 